\title{
Dimensionamento de um sistema para produção e purificação de biogás a partir de dejetos suínos
}

\author{
Anelise Cristine Scussel', Luis Antonio Rezende Muniz' \\ ' Universidade de Caxias do Sul (UCS). \\ E-mail: acscussel@ucs.br,muniz@upcontrol.com.br
}

Submetido em: 05 jul. 2019. Aceito: II out. 2019. DOI: http://dx.doi.org/I0.21674/2448-0479.6I.09-19

\section{Resumo}

A suinocultura é uma atividade que representa riscos ambientais, devido à quantidade de dejetos gerados. Um suíno com um porte de 25,00 a $100,00 \mathrm{~kg}$ produz aproximadamente 7,00 litros de dejetos líquidos. dia ${ }^{-1}$. A utilização de biodigestores para o tratamento de dejetos suínos reduz os poluentes liberados no meio ambiente e ainda produz biogás. Os resultados desse estudo referem-se ao projeto de uma unidade geradora de biometano para uma granja de 250 suínos, com vazão de $1,75 \mathrm{~m}^{3} \mathrm{dia}^{-1}$ de dejetos. Nessa unidade os dejetos são encaminhados para um reator Upflow Anaerobic Sludge Blanket (UASB) com altura de $6,00 \mathrm{~m}$ e diâmetro de $2,01 \mathrm{~m}$. No reator será realizada a digestão anaeróbia operando com temperatura de 30,00 a $35,00{ }^{\circ} \mathrm{C}$. A carga orgânica volumétrica (COV) adotada foi $3,35 \mathrm{kgDQO} \cdot \mathrm{m}^{-3} \cdot \mathrm{dia}^{-1}$ e a concentração de DQO solúvel $36,26 \mathrm{kgDQO} \cdot \mathrm{m}^{-3}$, com esses parâmetros foi obtido tempo de detenção hidráulica (TDH) de 259,75 horas e uma eficiência de remoção de DQO e DBO de 90,29 e 95,66 \% respectivamente. A produção volumétrica de biogás gerada no reator foi $22,54 \mathrm{~m}^{3}$. dia ${ }^{-1}$. Para remover $\circ \mathrm{H}_{2} \mathrm{~S}$ e o $\mathrm{CO}_{2}$ foi projetado um tanque de dessulfurização de 145,54 mm de altura e 83,17 mm de diâmetro, aplicando como agente dessulfurante lama de cal com vazão de 458,00 ml.dia ${ }^{-1}$, na qual é borbulhado o biogás. Após dessulfurado segue para a coluna de adsorção de I,29 m de altura e 64,30 mm de diâmetro, utilizando como adsorvente I.72I,95 g de carvão vegetal, para fazer a remoção da umidade.

Palavras-chave: Suinocultura. Dejetos suínos. Digestão anaeróbia. Reator UASB. Biogás.

\section{Abstract}

Swine breeding is an activity that represents risks to the environment due to the amount of waste generated. A pig weighing 25.00 to $100.00 \mathrm{~kg}$ produces approximately 7.00 liters of liquid waste.day ${ }^{\top}$. The use of biodigesters for the treatment of swine manure reduces pollutants and still produces biogas. The results of this study refer to the project of a biomethane generating unit for a farm of 250 swines, with a flow of $1.75 \mathrm{~m}^{3}$.day ${ }^{-1}$. In this unit the waste is sent to an Upflow Anaerobic Sludge Blanket (UASB) reactor with a height of $6.00 \mathrm{~m}$ and a diameter of $2.0 \mathrm{I} \mathrm{m}$. In the reactor the anaerobic digestion is performed in a temperature of 30.00 to $35.00{ }^{\circ} \mathrm{C}$. The volumetric organic load (VOL) adopted was $3.35 \mathrm{kgCOD} . \mathrm{m}^{-3}$. day ${ }^{-1}$ and the concentration of soluble COD $36.26 \mathrm{kgCOD} . \mathrm{m}^{-3}$, with these parameters was obtained hydraulic retention time (HRT) of $259.75 \mathrm{~h}$ and a removal efficiency of COD and BOD of 90.29 and 95.66 $\%$ respectively. The volumetric production of biogas generated in the reactor was $22.54 \mathrm{~m}^{3} . \mathrm{day}^{-1}$. To remove the $\mathrm{H}_{2} \mathrm{~S}$ and the $\mathrm{CO}_{2}$ a desulphurization tank $145.54 \mathrm{~mm}$ of height and $83.17 \mathrm{~mm}$ of diameter, applying as an agent of 
desulphurization lime mud with flow rate of $458.00 \mathrm{ml}^{-d a y}{ }^{-}{ }^{\prime}$, in which the biogas is bubbled. After desulphurization proceeds to the adsorption column of $1.29 \mathrm{~m}$ height and diameter of $64.30 \mathrm{~mm}$, using as adsorbent I,72I.95 g of charcoal to remove moisture.

Keywords: Swine breeding. Swine manure. Anaerobic digestion. UASB Reactor. Biogas.

\section{Introdução}

A suinocultura dedica-se à criação e exploração racional de suínos. Esta atividade socioeconômica vem crescendo progressivamente nos últimos anos no Brasil (MANFFESSONI, 2006). Os estados do Paraná, Santa Catarina e Rio Grande do Sul, são responsáveis por $80 \%$ das exportações, enquanto São Paulo e Minas Gerais estão mais direcionados para o mercado interno (DEPEC, 2007). (DEPARTAMENTO DE PESQUISAS E ESTUDOS ECONÔMICOS, 2007).

De acordo com Manfessoni (2006), o Brasil desfruta uma imensa extensão territorial para a produção de grãos e para suportar a deposição de dejetos suínos como fertilizantes. Contudo, em alguns estados do país, como Santa Catarina e Paraná já apontam saturação, sendo este o fator limitante à expansão da suinocultura.

Como os suínos demandam de grandes volumes de ração de alta qualidade nutricional e consomem muita água, geram esterco e urina com grandes concentrações de minerais e compostos orgânicos (DILDA et al., 2006). Os dejetos líquidos dos suínos contêm matéria orgânica, nitrogênio, fósforo, potássio, cálcio, sódio, magnésio, manganês, ferro, zinco, cobre, entre outros elementos inclusos nas dietas dos suínos (DIESEL; MIRANDA; PERDOMO, 2002). Segundo Oliveira (1994) a quantidade diária de dejetos líquidos gerados por um suíno com peso entre 25,00 - 100,00 kg corresponde a 7,00 l.dia`'.

Ainda hoje é frequente nos centros criadores de suínos, o aproveitamento dos dejetos como adubo orgânico, visto que esses dejetos são ótimos fertilizantes se empregados de forma correta (GASPAR, 2003). Contudo o emprego deste tipo de fertilizante natural sem um pré-tratamento não assegura a qualidade da adubação nem protege o meio ambiente da deterioração. Além disso, a criação de suínos também provoca a produção de mau cheiro, responsável por atrair grande número de insetos, muitos dos quais são prejudiciais à saúde da população rural e dos animais. Esse é um dos motivos pelos quais essa atividade rural está sujeita ao controle ambiental, por meio do licenciamento ambiental, cuja aplicação encontra-se prevista no art. 60 da Lei Federal n. 9.605/95 (GASPAR, 2003).

Alguns dos modelos dos biodigestores que podem ser empregados para o tratamento dos dejetos suínos são: o modelo Canadense (TORRES; PEDROSA; MOURA, 20I2), o reator do tipo Chinês (BORBA, 20I4), o reator do tipo Hindu (ANDRADE et al., 2002); e o reator anaeróbio de manta de lodo, conhecido como reator UASB (CHERNICHARO, 1997).

O reator UASB é muito utilizado para o tratamento dos dejetos suínos, pois possui um sistema compacto, com baixa demanda de área; baixo custo de implantação e de operação; baixa produção de lodo; satisfatória eficiência de remoção de DBO/DQO, da ordem de 65,00 - 75,00\% e possibilidade de rápido reinício, mesmo após longas paralisações (CHERNICHARO, 1997).

Simultaneamente ao tratamento dos dejetos, ocorre a produção de biogás e do biofertilizante. $O$ biofertilizante (lodo) gerado como efluente final, pode então, ser aplicado na agricultura sem prejudicar o solo, contudo deve-se fazer um estudo do solo da área que será aplicado o fertilizante a fim de estimar constituintes que estão em deficiência para atingir produtividade conforme o tipo de cultura desejada (FRIEHE; WEILAND; SCHATTAUER, 20I0; KARLSSON et al., 20I4). Já o biogás produzido, contém uma grande parte de metano e o restante de dióxido de carbono e sulfeto de hidrogênio, contém também outros constituintes, porém, em quantidades insignificantes. Por conta do $\mathrm{CO}_{2}$ e do $\mathrm{H}_{2} \mathrm{~S}$ faz-se necessário passar o biogás por outras etapas para a dessulfurização e remoção de dióxido de carbono, aumentando assim a quantidade de metano no produto final (FRIEHE; WEILAND; SCHATTAUER, 20I0; KARLSSON et al., 20I4).

objetivo do presente trabalho é projetar um sistema de produção e purificação de biogás utilizando dejetos suínos como matéria prima. Os objetivos específicos são:

- Definir as condições do processo, como o pH dos dejetos que alimentam o reator, a temperatura de operação do reator e do aquecedor, a carga orgânica volumétrica e a vazão diária de dejetos que entram no reator. 
- Dimensionar o reator UASB;

- Implantar a linha de produção de biogás;

- Dimensionar a unidade de tratamento e purificação do biogás, composto pelo sistema de dessulfurização e remoção de umidade.

\section{Material e Métodos}

Os experimentos foram realizados com utilização de dejetos suínos coletados em uma propriedade particular localizada na Linha Babilônia, pertencente ao município de São Pedro da Serra, no estado do Rio Grande do Sul (RS). A granja possuía um total de 250 suínos e lançava os dejetos através de uma boca de lobo até uma esterqueira. Vale ressaltar que os dejetos foram coletados em três etapas distintas, conforme a ração dada aos suínos, condiciona a respectiva fase de criação.

\section{Caracterização dos dejetos}

Os parâmetros analisados para a caracterização dos dejetos foram: umidade, carbono, nitrogênio total Kjedahl (NTK), fósforo, demanda química de oxigênio (DQO), demanda bioquímica de oxigênio (DBO), potássio, cálcio, magnésio, sólidos suspensos totais, sólidos suspensos voláteis, sólidos dissolvidos totais, sólidos dissolvidos fixos, sólidos dissolvidos voláteis, sólidos sedimentáveis, matéria orgânica, $\mathrm{pH}$ e densidade; realizados no Laboratório de Análises e Pesquisas Ambientais (LAPAM) da Universidade de Caxias do Sul - UCS. A análise de enxofre não foi realizada e, portanto, o percentual de enxofre foi obtido conforme a definição estipulada por Barker et al., (2002).

\section{Dimensionamento reator UASB}

Para o dimensionamento do reator UASB foram empregados os critérios de projetos descritos por Chernicharo (1997). Tal metodologia utiliza a Equação 2.I para calcular o volume do reator, Equação 2.2 para determinar o tempo de detenção hidráulica, Equação 2.3 para calcular a velocidade superficial, Equação 2.4 para encontrar a área do reator, Equação 2.5 para determinar o diâmetro do reator e a Equação 2.6 para obter a eficiência do reator UASB em termos de remoção de DQO.

$$
\begin{array}{r}
\text { Vreator }=\frac{\text { Qdejetos } \times \text { S0 }}{\text { COV }}(2.1) \\
\text { TDH }=\frac{\text { Vreator }}{\text { Qdejetos }}(2.2) \\
\mathrm{V}=\frac{\text { Hreator }}{\mathrm{TDH}}(2.3) \\
\text { Areator }=\frac{\text { Qdejetos }}{\mathrm{V}}(2.4) \\
\text { dreator }=\sqrt{\frac{\text { Areator } \times 4}{\pi}}(2.5) \\
\text { EDQO }=100 \times\left(1-0,68 \times \mathrm{TDH}^{-0,35}\right.
\end{array}
$$

Onde:

Vreator: volume total do reator $\left(\mathrm{m}^{3}\right)$;

Qdejetos: vazão total de dejetos $\left(\mathrm{m}^{3} \cdot\right.$ dia $\left.^{-1}\right)$;

S0: concentração de DQO afluente $\left(\mathrm{kgDQO} . \mathrm{m}^{-3}\right)$;

CVO: carga orgânica volumétrica $\left(\mathrm{kgDQO} \cdot \mathrm{m}^{-3} \cdot \mathrm{dia}^{-1}\right)$;

TDH: tempo de detenção hidráulica (dia);

$\mathrm{v}$ : velocidade superficial ou velocidade ascensional (m.dia $\left.{ }^{-1}\right)$;

Hreator: diâmetro do reator $(\mathrm{m})$;

dreator: diâmetro do reator $(\mathrm{m})$;

Areator: área da seção transversal do reator $\left(\mathrm{m}^{2}\right)$; 
EDQO: eficiência do reator UASB em termos de remoção de DQO (\%);

0,68: constante empírica;

0,35: constante empírica.

A determinação da taxa mássica de DQO convertida em gás metano foi obtida através do balanço de massa global esquematizado pela Figura 2.I e apresentado pela Equação 2.7.

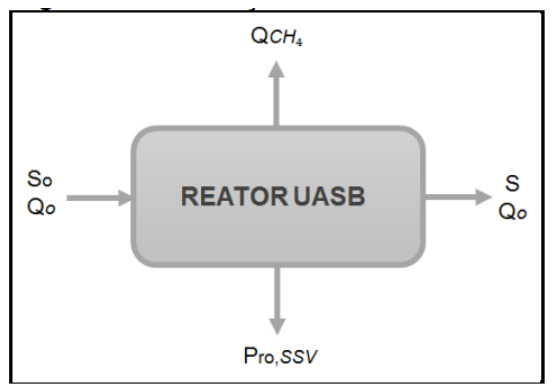

Figura 2.I

Balanço de massa do reator

Fonte: Adaptado de Chernicharo (1997).

$\dot{\mathrm{m} D Q O} \mathrm{CH}_{4}=\dot{\mathrm{mDQO}} 0-(\dot{\mathrm{m} D Q O} s+\dot{\mathrm{m} D Q O} s s v)$

Onde:

mDQO $\mathrm{CH}_{4}$ : taxa mássica de DQO convertida em metano $\left(\mathrm{kgDQOCH}_{4} \cdot \mathrm{dia}^{-1}\right)$;

mDQO $O$ : taxa mássica de DQO inicial (kgDQOo.dia $\left.{ }^{-1}\right)$;

ṁQOS: taxa mássica de DQO final (kgDQOs. $\left.\mathrm{dia}^{-}{ }^{-}\right)$;

ṁDQSSV: taxa mássica de DQO convertida em sólidos suspensos voláteis (kgDQOSSV.dia ${ }^{-1}$ ).

A produção volumétrica de metano também foi obtida aplicando a relação apresentada na Equação (2.8).

$$
\mathrm{QCH}_{4}=\dot{\mathrm{mDQOCH}} \mathrm{H}_{4} \times 0,35 \mathrm{~m}^{3}
$$

Onde:

$\mathrm{QCH}_{4}$ : produção volumétrica de metano $\left(\mathrm{m}^{3} \cdot \mathrm{dia}^{-1}\right)$;

mDQO $\mathrm{CH}_{4}$ : taxa mássica de DQO convertida em metano $\left(\mathrm{kgDQOCH}_{4} \cdot \mathrm{dia}^{-1}\right)$.

A produção volumétrica esperada de biogás foi determinada empregando a Equação 2.9.

$$
\text { Qbiogás }=\frac{\mathrm{QCH}_{4}}{0,66}
$$

Onde:

Qbiogás: produção volumétrica de biogás $\left(\mathrm{m}^{3} \cdot \mathrm{dia}^{-1}\right)$;

$\mathrm{QCH}_{4}$ : produção volumétrica de metano $\left(\mathrm{m}^{3} \cdot \mathrm{dia}^{-1}\right)$;

0,66: constante estequiométrica.

\section{Dimensionamento do dessulfurizador}

Machado et al. (2015) afirmam que, pode ser utilizado uma técnica que aplica lama de cal para retirar o sulfeto de hidrogênio do biogás. A reação do $\mathrm{Ca}(\mathrm{OH})_{2}$ com $\circ \mathrm{H}_{2} \mathrm{~S}$ produz sulfeto de cálcio e água, como mostra a Equação 2.10.

$$
\mathrm{Ca}(\mathrm{HO})_{2}+\mathrm{H}_{2} \mathrm{~S} \rightarrow \mathrm{CaS} \downarrow+\mathrm{H}_{2} \mathrm{O} \quad(2.10)
$$

Os parâmetros operacionais do processo foram definidos de acordo com a abordagem teórica de Skoog et al. (2006). A partir da Equação 2. I I foi encontrada a massa de hidróxido de cálcio necessária para preparar a lama de cal. 


$$
\eta \mathrm{H}_{2} \mathrm{~S}=\eta \mathrm{Ca}(\mathrm{OH})_{2} \rightarrow \eta \mathrm{H}_{2} \mathrm{~S}=\frac{\mathrm{mCa}(\mathrm{OH})_{2}}{\operatorname{MMCa}(\mathrm{OH})_{2}}
$$

Onde:

$\mathrm{H}_{2} \mathrm{~S}$ : número de mols de sulfeto de hidrogênio (mol);

$\mathrm{Ca}(\mathrm{OH})_{2}$ : número de mols de hidróxido de cálcio $(\mathrm{mol})$;

$\mathrm{mCa}(\mathrm{OH})_{2}$ : massa de hidróxido de cálcio $(\mathrm{g})$;

$\mathrm{MMCa}(\mathrm{OH})_{2}$ : massa molecular do hidróxido de cálcio (g.mol $\left.{ }^{-\top}\right)$.

O dimensionamento do dessulfurizador seguiu os fundamentos propostos por Pimentel (20I2). Definindo as horas de atividade e a vazão da lama foi encontrado o volume do tanque de dessulfurização pela Equação 2.12.

$$
\text { Vtanque }=\text { Qlama } \mathrm{X} \text { htrab }(2.12)
$$

Onde:

Vtanque: volume do tanque $\left(\mathrm{m}^{3}\right)$;

Qlama: vazão volumétrica da lama $\left(\mathrm{m}^{3} \cdot \mathrm{h}^{-1}\right)$;

htrab: horas de trabalho $(h)$.

As Equações 2.13 e 2.14 correspondem respectivamente aos cálculos realizados para a determinação do diâmetro e da altura do tanque de dessulfurização.

$$
\begin{aligned}
& \text { Dtanque }=\sqrt[3]{\frac{4 \times V \text { tanque }}{\pi \times 1,75}} \\
& \text { Htanque }=1,75 \times \text { Dtanque }
\end{aligned}
$$

Onde:

Dtanque: diâmetro do tanque $(\mathrm{m})$;

Htanque: altura do tanque $(\mathrm{m})$.

\section{Dimensionamento da coluna de carvão}

Conhecendo o tempo de residência e a vazão do gás na entrada da coluna foi calculado o volume da coluna de secagem utilizando a Equação 2.I5.

$$
\text { Vcoluna }=\text { tres } \times \text { Qen,gás }
$$

Onde:

Vcoluna: volume da coluna $\left(\mathrm{m}^{3}\right)$;

tres: tempo de residência (s);

Qen,gás: vazão de gás na entrada $\left(\mathrm{m}^{3} \cdot \mathrm{s}^{-1}\right)$.

O diâmetro e a altura da coluna de carvão foram determinados aplicando as Equações 2.16 e 2.17, seguindo a abordagem de Pimentel (2012). A massa de carvão utilizada como recheio da coluna foi obtida segundo Garcia (20|4), aplicando a Equação 2.18.

$$
\begin{gathered}
\text { Dcoluna }=\sqrt[3]{\frac{4 \times V_{\text {coluna }}}{\pi \times 20}} \\
\text { Hcoluna }=20 \times \text { Dcoluna } \\
\text { mad }=\frac{q}{\text { Cap }}
\end{gathered}
$$


Onde:

Dcoluna: diâmetro da coluna $(m)$;

Hcoluna: altura da coluna $(m)$;

mad: massa de adsorvente (g);

q: massa de umidade adsorvida (g);

Cap: capacidade de adsorção ( $\mathrm{g}$ de $\mathrm{H} 2 \mathrm{O} \cdot \mathrm{g}^{-1}$ de carvão).

\section{Dimensionamento do aquecedor}

Para determinar a carga térmica do aquecedor, primeiramente foi necessário determinar a capacidade calorífica dos dejetos suínos através do ensaio de Calorimetria Exploratória Diferencial (DSC) realizado no Laboratório de Polímero (LPol), da UCS. O calor específico foi calculado aplicando a Equação 2.19, de acordo com Carvalho (2017).

$$
\mathrm{Cp}(\text { dejetos })=\frac{\mathrm{D}}{\text { mdejetos }_{\mathrm{W}}} \times \frac{\mathrm{m}_{\text {safira }}}{\mathrm{W}} \times \mathrm{Cp} \text { safira }
$$

Onde:

$\mathrm{Cp}$ (dejetos): calor específico da amostra $\left(\mathrm{J} \cdot\left[\mathrm{g} \cdot{ }^{\circ} \mathrm{C}\right]^{-1}\right)$;

D: diferença entre o fluxo de calor associado à amostra em determinada temperatura $(\mathrm{mW})$ e o fluxo de calor associado à linha base em determinada temperatura $(\mathrm{mW})$;

mdejetos: massa da amostra (mg);

msafira: massa do padrão de safira $(\mathrm{mg})$;

W: diferença entre o fluxo de calor associado ao padrão de safira em determinada temperatura $\mathrm{mW}$ ) e o fluxo de calor associado à linha base em determinada temperatura $(\mathrm{mW})$;

Cpsafira: calor específico do padrão de safira em determinada temperatura (tabelado) $\left(\mathrm{J} \cdot\left[\mathrm{g} \cdot{ }^{\circ} \mathrm{C}\right]^{-1}\right)$.

Aplicando a Equação 2.20 foi determinada a carga térmica do aquecedor.

$$
\text { Qcarga }=\dot{\mathrm{m}} \times \text { Cpdejetos } \times\left(\mathrm{Tf}-\mathrm{Ti}_{\mathrm{i}}\right)
$$

Onde:

Qcarga: carga térmica $(\mathrm{W})$;

Cpdejetos: calor específico dos dejetos suínos $\left(J \cdot\left[\mathrm{kg} .{ }^{\circ} \mathrm{C}\right]^{-\top}\right)$;

m: taxa mássica de dejetos $\left(\mathrm{kg} \cdot \mathrm{s}^{-1}\right)$;

Tf: Temperatura final dos dejetos $\left({ }^{\circ} \mathrm{C}\right)$;

Ti: Temperatura inicial dos dejetos $\left({ }^{\circ} \mathrm{C}\right)$.

\section{Resultados e Discussões}

A unidade projetada não utiliza esterqueira para armazenagem de dejetos, sendo estes encaminhados diretamente da boca de lobo para o reator UASB. O biogás gerado segue então, para a primeira etapa de purificação onde são removidos o sulfeto de hidrogênio e o dióxido de carbono.

O biogás dessulfurado passa para a etapa de secagem utilizando uma coluna de adsorção recheada de carvão, na qual é removida a umidade presente no biogás. Como a unidade vai ser operada com apenas uma coluna de carvão, quando ocorrer saturação, esta será substituída por outra até a sua regeneração.

O fluxograma do processo de obtenção e purificação do biogás está ilustrado na Figura 3.I. O Quadro 3.I apresenta os equipamentos empregados no processo e suas correntes envolvidas.

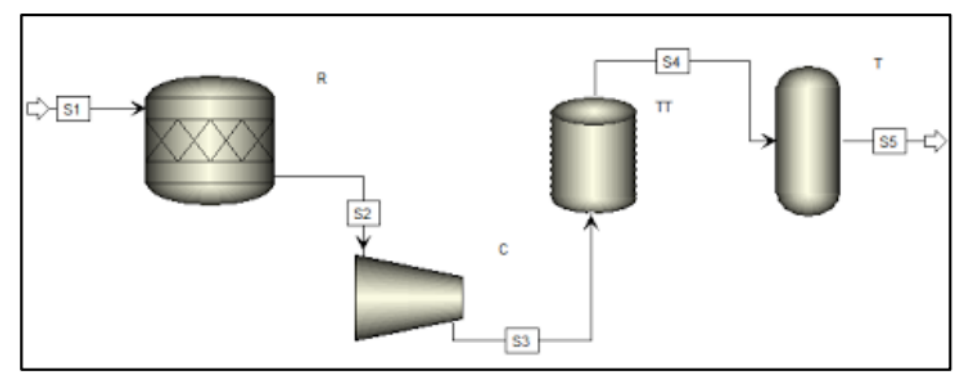

Fonte: Autor (2017).
Figura 3.I

Fluxograma do processo 


\begin{tabular}{|l|c|c|}
\hline \multirow{4}{*}{ Equipamentos } & $\mathrm{R}$ & Reator UASB \\
\cline { 2 - 3 } & $\mathrm{C}$ & Compressor \\
\cline { 2 - 3 } & $\mathrm{TT}$ & Tanque \\
\cline { 2 - 3 } & $\mathrm{T}$ & Coluna \\
\hline \multirow{5}{*}{ Correntes } & $\mathrm{S} 1$ & Dejetos líquidos \\
\cline { 2 - 3 } & $\mathrm{S} 2$ & Biogás \\
\cline { 2 - 3 } & $\mathrm{S} 3$ & Biogás \\
\cline { 2 - 3 } & $\mathrm{S} 4$ & Gás sem $\mathrm{H}_{2} \mathrm{Se} \mathrm{CO}_{2}$ \\
\cline { 2 - 3 } & $\mathrm{S} 5$ & Gás purificado \\
\hline
\end{tabular}

Fonte: Autor (20I7).

De acordo com as análises realizadas, o pH dos dejetos que alimentam o reator estão em torno de 7,02, sendo esse um ótimo valor de $\mathrm{pH}$ para o processo. Segundo Chernicharo (1997) a temperatura de operação do reator deve ficar entre $30-35^{\circ} \mathrm{C}$, para isso pode ser empregado um aquecedor térmico, que conforme os cálculos desse trabalho, necessita ter uma carga térmica de 4,20 W.

Para o cálculo do aquecedor foi empregado o calor específico dos dejetos encontrado com o auxilio do ensaio da DSC (6.820,0 J.[kg. $\left.\left.{ }^{\circ} \mathrm{C}\right]^{-1}\right)$. Também foi definida uma faixa ideal de temperatura de 5,00 - 35,00 ${ }^{\circ} \mathrm{C}$. A temperatura inicial dos dejetos baixa, em $5,00^{\circ} \mathrm{C}$, foi definida para que o aquecedor tenha capacidade térmica de trabalhar tanto no inverno quanto no verão.

\section{Resultados das análises}

A primeira amostra analisada corresponde a uma alimentação de alojamento e crescimento I, a segunda amostra a uma alimentação com ração de crescimento 2 , 3 e 4 - e por fim, a terceira amostra corresponde a alimentação com ração de terminação I e 2 . As diferentes concentrações obtidas analisando as amostras I, 2 e 3 se deve pelos diferentes nutrientes presentes em cada tipo de ração. Scussel e Muniz (2017) realizaram triplicatas para cada amostra analisada e posteriormente fizeram uma média, obtendo os resultados apresentados na Tabela 4.I.

Tábela 4.I - Dados obtidos nas análises dos dejetos

\begin{tabular}{|c|c|c|c|c|}
\hline Análise & Amostra I & Amostra 2 & Amostra 3 & Unidade \\
\hline Mat. Orgânica & $8.810,67$ & $34.377,33$ & $267.072,0$ & $\mathrm{mgO}_{2} \cdot \mathrm{I}^{-1}$ \\
\hline DQO total & $25.114,00$ & $59.081,67$ & $33.095,67$ & $\mathrm{mgO}_{2} \cdot \mathrm{I}^{-1}$ \\
\hline DQO filtrado & $17.675,00$ & $36.260,33$ & $32.260,67$ & $\mathrm{mgO}_{2} \cdot \mathrm{I}^{-1}$ \\
\hline DBO total & $9.028,87$ & $25.230,53$ & $17.579,87$ & $\mathrm{mgO}_{2} \cdot \mathrm{I}^{-1}$ \\
\hline DBO filtrado & $12.774,33$ & $15.163,87$ & $11.874,53$ & $\mathrm{mgO}_{2} \cdot \mathrm{I}^{-1}$ \\
\hline SST & $7.296,67$ & $32.511,10$ & $12.0874,53$ & $\mathrm{mg} . \mathrm{I}^{-1}$ \\
\hline SSV & $5.896,67$ & $26.494,33$ & $10.416,67$ & $\mathrm{mg} \cdot \mathrm{I}^{-1}$ \\
\hline SDT & $7.603,33$ & $13.661,10$ & $16.166,67$ & $\mathrm{mg} . \mathrm{I}^{-1}$ \\
\hline SDF & $4.250,00$ & $6.938,77$ & $8.983,33$ & $\mathrm{mg} \cdot \mathrm{I}^{-1}$ \\
\hline SDV & $3.353,33$ & $6.722,23$ & $7.183,33$ & $\mathrm{mg} . \mathrm{I}^{-1}$ \\
\hline Sedimentáveis & 70,00 & Prejudicado & Prejudicado & $\mathrm{mg} \cdot \mathrm{I}^{-1}$ \\
\hline Carbono & 42,42 & 42,01 & 41,00 & $\%$ \\
\hline Umidade & 36,37 & 72,13 & 64,17 & $\%$ \\
\hline Nitrogênio total & $9.643,15$ & $6.007,12$ & $5.328,15$ & $\mathrm{mgNH}_{3}-\mathrm{N} . \mathrm{I}^{-1}$ \\
\hline $\mathrm{pH}$ & 7,02 & 7,79 & 7,85 & n.a \\
\hline Potássio & 521,65 & $4.142,367$ & $3.66 I, 55$ & $\mathrm{mgK}^{-I^{-1}}$ \\
\hline Cálcio & 298,93 & 911,33 & 248,13 & $\mathrm{mg} . \mathrm{I}^{-1}$ \\
\hline Magnésio & 38,11 & 772,17 & 508,67 & $\mathrm{mg} . \mathrm{I}^{-1}$ \\
\hline Fósforo & 352,37 & $1.372,62$ & $1.999,01$ & mgP..$^{-1}$ \\
\hline Densidade & 1,01 & 1,02 & $|, 0|$ & $\mathrm{g} \cdot \mathrm{cm}^{-3}$ \\
\hline
\end{tabular}

Fonte: Autor (2017) 
Para fins de desenvolvimento do projeto foram desconsiderados os resultados da amostra 3, pois a essa possui valores intermediários as outras duas. A amostra I também não foi selecionada para realização do projeto, pois essa não seria eficiente para remover a carga orgânica quando os suínos fossem alimentados com a ração de crescimento. Então o projeto foi calculado utilizando os resultados da amostra 2, por essa ser a fase mais longa, a fase de crescimento.

\section{Projeto reator UASB}

A vazão de dejetos líquidos na granja foi de $1,75 \mathrm{~m}^{3} \cdot \mathrm{dia}^{-1}$, considerando uma criação de 250 suínos. O volume do reator obtido, para esta vazão foi de $18,94 \mathrm{~m}^{3}$ aplicando carga orgânica volumétrica de 3,35 $\mathrm{kgDQO} \cdot \mathrm{m}^{-3} \cdot \mathrm{dia}^{-1}$ e uma concentração máxima de DQO solúvel afluente de 36,26 $\mathrm{kgDQO} \cdot \mathrm{m}^{-3}$, determinada através dos ensaios realizados no LAPAM. Valores mais baixos de COV acarretam em um reator com maior volume, visto que, mais água será necessário adicionar para equilibrar a diferença entre a redução diária e o volume de alimentação (TAIGANIDES, 1992).

Nesse trabalho foi encontrado um tempo de detenção hidráulica de 10 dias, 19 horas e 41 minutos, quando a concentração de DQO for máxima. Conforme Taiganides, (1992) valores de tempo de detenção hidráulica compreendidos entre 4 - 6 dias são considerados ideais para águas residuais de suínos.

Segundo Chernicharo (1997) a altura ideal de um reator UASB está compreendida entre 4,00 e 5,50 m, entretanto essa recomendação é para o tratamento de esgotos domésticos e não para dejetos suínos. Como o volume determinado do reator ficou em $18,94 \mathrm{~m}^{3}$, para que o diâmetro não ficasse muito grande foi estabelecida uma altura de 6 metros, sendo definida a altura do compartimento de decantação em 2,25 m, e a altura do compartimento de digestão em 3,75 m, encontrando assim um diâmetro de 2,0 1 m.

Oliveira et al., (2009) operando dois reatores UASB em série, e aplicadas cargas orgânicas volumétricas crescentes no sistema de 5,60 a 69,80 kgDQOtotal. $\mathrm{m}^{-3}$. dia ${ }^{-1}$, obtiveram eficiência de remoção de DQO total e de DQO solúvel no sistema de 89,00 e 91,00 \% quando empregado uma COV de 5,6 kgDQOtotal. $\mathrm{m}^{-3} \cdot \mathrm{dia}^{-1}$.

A eficiência de remoção de DQO observado neste projeto foi 90,29 \% para a DQO solúvel e 95,66 \% para a DBO solúvel, assemelhando-se ao encontrado por Oliveira et al., (2009).

A taxa mássica de metano gerada foi $42,50 \mathrm{kgDQOCH}_{4} \cdot \mathrm{dia}^{-}$. A conversão da produção mássica para produção volumétrica foi de $14,88 \mathrm{~m}^{3} \cdot \mathrm{dia}^{-1}$ de metano e de $22,54 \mathrm{~m}^{3} \cdot \mathrm{dia}^{-1}$ de biogás. Nesse projeto foi adotada uma concentração de $66,00 \%$ de metano e 33,94 \% de dióxido de carbono, tais valores seguem as recomendações de Friehe, Weiland e Schattauer (2010), onde citam que o biogás geralmente possui uma fração de 50,00 a $75,00 \%$ de metano e 25,00 a $50,00 \%$ de $\mathrm{CO}_{2}$ em sua composição. Além do metano e do dióxido de carbono foi estabelecido que o biogás deve conter uma concentração igual a 600 partes por milhão (ppm) de sulfeto de hidrogênio, sendo este o pior caso, já que esta concentração é letal segundo Barker et al. (2002).

Não foram levados em consideração outros compostos químicos, visto que esses compostos possuem uma porcentagem desprezível em relação aos compostos citados a cima.

\section{Projeto tanque de dessulfurização}

Para o projeto do tanque de dessulfurização foi considerado o pior caso, quando o biogás gerado contém $0,06 \%$ de $\mathrm{H}_{2} \mathrm{~S}$ e para removê-lo foi empregado lama de cal composta por hidróxido de cálcio e água, assim o sulfeto de hidrogênio reage com o hidróxido de cálcio formando sulfeto de cálcio, que pode ser oxidado a sulfato de cálcio e aplicado como insumo na agricultura. Como o $\mathrm{CO}_{2}$ é solúvel em água, é removido do biogás, aumentando a concentração de metano.

Para fazer a remoção do sulfeto de hidrogênio e do dióxido de carbono foi estabelecida uma vazão de $458,00 \mathrm{ml} \cdot \mathrm{dia}^{-1}$ de lama de cal, que deve ser preparada com 17,50 ml de água e, 3,50 g de hidróxido de cálcio, obtendo assim, uma massa específica de $1.100,40 \mathrm{~kg} \cdot \mathrm{m}^{-3}$.

Foi definido que o tanque de dessulfurização trabalha $4 \mathrm{I}, 4 \mathrm{I}$ horas, após esse tempo é necessário adicionar mais lama de cal, tornando possível determinar as dimensões do tanque com o uso dos seguintes parâmetros: diâmetro de $83,17 \mathrm{~mm}$ e altura de 145,54 mm, logo o volume total será de $790 \mathrm{ml}$. 


\section{Projeto coluna de carvão}

Para dimensionar a coluna de adsorção primeiramente foi definido um tempo de residência igual a 16 segundos, estando esse valor dentro da faixa ( 3 a 30 segundos) sugerida por Perry e Chilton (1980). Também foi adotado que a altura da coluna é 20 vezes maior que o diâmetro e a partir desses dados foi determinado que a coluna que deverá ter um diâmetro de $64,30 \mathrm{~mm}$ e uma altura de I,29 $\mathrm{m}$. A remoção da umidade presente no biogás será feita utilizando I.72I,95 g de carvão.

\section{Materiais para a construção}

O reator UASB, o tanque de dessulfurização e a coluna de carvão, podem ser construídos empregando tubos rígidos de policloreto de vinila (PVC), visto que o material apresenta resistência à corrosão, intrínseca ao próprio material ou também pode ser usado fibra de vidro.

\section{Pós dessulfurização e adsorção}

No trabalho de Machado et al. (20I5) houve uma diminuição nos índices de $\mathrm{CO}_{2}$ de 10,50 \% para 7,20 \% e de $\mathrm{H}_{2} \mathrm{~S}$ de 2,50 \% para I,70 \% após o biogás passar pelos filtros de cal e carvão. A redução da concentração de $\mathrm{CO}_{2}$ na saída do sistema de filtragem ocorreu devido ao dióxido de carbono ser solúvel em água, aumentando assim a concentração de metano de $87,00 \%$ para $91,00 \%$ na mistura do biogás.

Semelhante a Machado et al. (20I5) foi definido que nesse estudo houve uma redução de sulfeto de hidrogênio de 600 para I ppm e de dióxido de carbono de 33,94 \% para 7,84 \%, desta forma foi estabelecido que o metano passou de 66,00 para 92,16\%.

\section{Aplicações}

Conforme Filho (198I), o poder calorífico do biometano pode alcançar até $50.208,00 \mathrm{~kJ} \cdot \mathrm{m}^{-3}$, sendo estipulado para este projeto, $41.840,00 \mathrm{~kJ} \cdot \mathrm{m}^{-3}$, ou seja, há um aproveitamento de II,62 kW.h.m ${ }^{-3}$. Então, com a produção volumétrica do biometano $14,88 \mathrm{~m}^{3}$. $\mathrm{dia}^{-}{ }^{-1}$, foi estimada a produção máxima de energia de 172,91 kW.h.dia ${ }^{-1}$ ou 5.187I,30 kW.h.mês ${ }^{\top 1}$.

Considerando o estudo realizado por Dall Agnol (20l3), o consumo médio de energia por residência corresponde a aproximadamente $170,00 \mathrm{~kW}$.h.mês ${ }^{-1}$, isso significa que o projeto possui capacidade de atender uma população de 30 residências populares, ou o biometano pode ser utilizado como gás de cozinha, com base em Pergher (2006), o presente projeto tem possibilidade de produzir o equivalente a I5 botijões de gás com capacidade $\mathrm{P}-13$ por mês.

Porém nesses cálculos não foi subtraído a quantidade de energia que o aquecedor utiliza, portanto para um melhor controle de temperatura ideal, recomenda-se a implementação de um controlador.

\section{Considerações Finais}

A escolha do reator UASB mostrou-se eficiente quando empregado para tratar águas residuais da suinocultura, pois além de gerar biogás produz um lodo, que pode ser aplicado na agricultura.

O projeto demonstrou eficiência na remoção de DQO e DBO solúvel de 90,29 e 95,66 \%, respectivamente, enquanto que a vazão máxima de biogás gerada foi $22,54 \mathrm{~m}^{3}$.dia ${ }^{-1}$ e a mínima $10,65 \mathrm{~m}^{3}$.dia ${ }^{-1}$, dependendo da fase de criação dos suínos e, consequentemente, da ração ofertada. Outro ponto positivo foi a facilidade e baixo custo de construção e manutenção do tipo de reator dimensionado, quando comparado com os reatores do tipo Chinês, Hindu ou Canadense.

A ideia desse projeto foi gerar biogás, com uma qualidade que seja associada ao seu custo de produção, bem como o custo de implantação, operação e manutenção da unidade. Por esses motivos foram selecionados para a purificação do biogás, o tanque de lama de cal para remover o sulfeto de hidrogênio e o dióxido de carbono e, a coluna de carvão para remoção da umidade. Por fim concluiu-se que a unidade dimensionada possui capacidade máxima de gerar energia para atendimento de 30 residências populares mensalmente ou produzir I 5 botijóes de gás P-I 3 por mês, porém sem levar em conta a energia que o aquecedor consome. 


\section{Referências}

ANDRADE, M. A. N et al. Biorreatores rurais no contexto da atual crise de energia elétrica brasileira e na perspectiva da sustentabilidade ambiental. In: 4 ENCONTRO DE ENERGIA NO MEIO RURAL - AGRENER, 2002, Campinas, SP. Anais [...]. Campinas: UNICAMP, 2002.

BARKER, J. et al. Safety in swine productions systems. Pork industry handbook, North Carolina, mar. 1982.

BORBA, A.P. Estudo de materiais metálicos para a fabricação de biorreatores anaeróbios. 20I4. I40 f. Dissertação (Mestrado em Engenharia, Área de Concentração de Processos de Fabricação, modalidade Acadêmica) - Programa de Pós-Graduação em Engenharia de Minas, Metalúrgica e de Materiais - Escola de Engenharia, Universidade Federal do Rio Grande do Sul, Porto Alegre, RS, 2014.

CARVALHO, G. A. Técnicas de caracterização de polímeros. Calorimetria exploratória diferencial. In: Apostila 2017/04. Caxias do Sul, RS: Universidade de Caxias do Sul, 2017. p. 19-23.

CHERNICHARO, C.A.L. Reatores anaeróbios. v. 5. Belo Horizonte: Departamento de Engenharia Sanitária e Ambiental - UFMG, 1997.

DALL AGNOL, V. Dimensionamento de um reator anaeróbio de manta de lodo (UASB) para produção de biogás. 20I3. 60 f. Trabalho de Conclusão de Curso (Graduação em Engenharia Química, Área de Conhecimento de Ciências Exatas e Engenharias) - Universidade de Caxias do Sul, Caxias do Sul, RS, 2013.

DEPARTAMENTO DE PESQUISAS E ESTUDOS ECONÔMICOS (Brasil) - DEPEC. Carne suína. Bradesco, 2007. Disponível em: https://www.economiaemdia.com.br/EconomiaEmDia/pdf/infset_carne_suina.pdf. Acesso em: 20 abr. 2017.

DIESEL, R;. MIRANDA, C. R; PERDOMO, C.C. Boletim informativo BIPERS: coletânea de tecnologias sobre dejetos suínos. Semestral. Ano 10, n. I4. Concórdia, SC: EMATER, ago. 2002.

DILDA, C. et al. Projeto: controle da contaminação ambiental decorrente da suinocultura no Rio Grande do Sul. 2.ed. Passo Fundo, RS: UPF, 2006.

FILHO, J. A. C. Biogás, independência energética do Pantanal Mato - Grossense. n.9. Corumbá, MS: EMBRAPA, I981.

FRIEHE, J.; WEILAND, P.; SCHATTAUER, A. Fundamentos da fermentação anaeróbia. In: FILHO, J.C.A. Guia prático do biogás, geração e utilização. 5. ed. Corumbá, MS: FNR, 20I0. p. 20-30.

GARCIA, C. G. Montagem e operação de unidade de adsorção em leito fixo para remoção de $\mathbf{H} 20$ de corrente gasosa. 2014. 92 f. Dissertação (Mestrado em Engenharia Hidráulica e Saneamento, Departamento de Hidráulica e Saneamento) - Escola de Engenharia de São Carlos, da Universidade de São Paulo, São Carlos, SP, 2014.

GASPAR, R. M. B. L. Utilização de biodigestores em pequenas e médias propriedades rurais com ênfase na agregação de valor: um estudo de caso na região de Toledo-PR. 2003. I0I f. Dissertação (Mestrado em Engenharia de Produção, Área de Concentração: Planejamento e Estratégia Organizacional.) - Programa de Pós-Graduação em Engenharia de Produção, Universidade Federal de Santa Catarina, Florianópolis, SC, 2003.

KARLSSON, T. et al. Manual básico de biogás. Lajeado, RS: UNIVATES, 2014.

MACHADO, N. S et al. Remoção do sulfeto de hidrogênio do biogás da fermentação anaeróbia de dejetos de suínos utilizando óxido de ferro, hidróxido de cálcio e carvão vegetal. Revista Energia na Agricultura, Botucatu, SP, v. 30, n. 4 , p. $334-356$, out/dez. 2015.

MANFESSONI, E. L. Manual prático de suinocultura. 2. ed. Porto Alegre, 2006.

OLIVEIRA, P. A. V. Impacto ambiental causado pelos dejetos de suínos. In: SIMPÓSIO LATINO AMERICANO DE NUTRIÇÃO DE SUÍNOS, 1994, Campinas, SP. Anais [...]. Campinas:,CBNA, 1994. p. 27- 40.

PERGHER, G. D. Purificação de biogás. In: REUNIÃO TÉCNICA SOBRE BIODIGESTORES PARA TRATAMENTO DE DEJETOS DE SUÍNOS E USO DE BIOGÁS, 2006, Concórdia, SC. Anais [...]. Concórdia: EMBRAPA, 2006. p. I3-19.

PERRY, R. H.; CHILTON, C. H. Manual de engenharia química. 5. ed. Rio de Janeiro: Guanabara, 1980.

PIMENTEL, A. C. Projeto de semi dry scrubber para controle de poluição atmosférica de gases amina provenientes do processo de fundição. 2012. 80 f. Trabalho de Conclusão de Curso (Graduação em Engenharia Química, Área de Conhecimento de Ciências Exatas e Engenharias) - Universidade de Caxias do Sul, Caxias do Sul, RS, 2012. 
SCUSSEL, A. C.; MUNIZ, L. A. R. Dimensionamento de um sistema de obtenção e purificação de biogás a partir de dejetos suínos. 2017. 92 f. Trabalho de Conclusão de Curso (Graduação em Engenharia Química, Área de Conhecimento de Ciências Exatas e Engenharias) - Universidade de Caxias do Sul, Caxias do Sul, RS, 2017.

SKOOG, A. D.; WEST, D. M.; HOLLER, F. J.; CROUCH, S. R. Fundamentos de química analítica. 8 ed. São Paulo: Thomson, 2006.

TAIGANIDES, E. P. Pig waste management and recycling: the Singapore experience. Ottawa: International Development Research Centre, 1992.

TORRES, A.; PEDROSA, J. F.; MOURA, J. P. Fundamentos de implantação de biodigestores em propriedades rurais. Educação Ambiental em ação, ano I I, n. 40, jun./ago. 2012. Disponível em: http://www.revistaea.org/artigo.php?idartigo $=1248$. Acesso em: 14 nov. 2017. 